\section{( OPEN ACCESS}

\title{
Perception of slipperiness and prospective risk of slipping at work
}

\author{
Theodore K Courtney, ${ }^{1,2}$ Santosh K Verma ${ }_{1}^{1,3}$ Wen-Ruey Chang, ${ }^{4}$ Yueng-Hsiang Huang, ${ }^{5}$ \\ David A Lombardi, ${ }^{1,2}$ Melanye J Brennan, ${ }^{1}$ Melissa J Perry ${ }^{2,6}$
}

\begin{abstract}
${ }^{1}$ Center for Injury Epidemiology, Liberty Mutual Research Institute for Safety, Hopkinton, Massachusetts, USA

${ }^{2}$ Environmental and Occupational Medicine and Epidemiology Program, Department of Environmental Health, Harvard School of Public Health, Boston, Massachusetts, USA

${ }^{3}$ Department of Family Medicine and Community Health, University of Massachusetts Medical School, Worcester, Massachusetts, USA ${ }^{4}$ Center for Physical Ergonomics, Liberty Mutual Research Institute for Safety, Hopkinton, Massachusetts, USA

${ }^{5}$ Center for Behavioral Sciences, Liberty Mutual Research Institute for Safety, Hopkinton, Massachusetts, USA

${ }^{6}$ Department of Environmental and Occupational Health, The George Washington University, Washington DC, USA
\end{abstract}

\section{Correspondence to} Theodore K Courtney, Center for Injury Epidemiology, Liberty Mutual Research Institute for Safety, 71 Frankland Rd., Hopkinton, MA 01748, USA; theodore.courtney@ LibertyMutual.com

Received 6 April 2012 Revised 4 July 2012 Accepted 30 July 2012 Published Online First 29 August 2012

\footnotetext{
To cite: Courtney TK, Verma SK, Chang W-R, et al. Occup Environ Med 2013, 70, 35-40.
}

\section{ABSTRACT \\ Objectives Falls are a leading cause of injury at work, and slipping is the predominant cause of falling. Prior research has suggested a modest correlation between objective measures (such as coefficient of friction, COF) and subjective measures of slipperiness (such as worker perceptions) in the workplace. However, the degree of association between subjective measures and the actual risk of slipping at the workplace is unknown. This study examined the association between perception of slipperiness and the risk of slipping.}

Methods 475 workers from 36 limited-service restaurants participated in a 12-week prospective cohort study. At baseline, demographic information was collected, participants rated floor slipperiness in eight areas of the restaurant, and work environment factors, such as COF, were measured. Restaurant-level and arealevel mean perceptions of slipperiness were calculated. Participants then reported their slip experience at work on a weekly basis for the next 12 weeks. The associations between perception of slipperiness and the rate of slipping were assessed.

Results Adjusting for age, gender, body mass index, education, primary language, mean COF, use of slipresistant shoes, and restaurant chain, each 1-point increase in mean restaurant-level perception of slipperiness (4-point scale) was associated with a 2.71 times increase in the rate of slipping $(95 \% \mathrm{Cl} 1.25$ to 5.87). Results were similar for area-level perception within the restaurant (rate ratios (RR) $2.92,95 \% \mathrm{Cl}$ 2.41 to 3.54 ).

Conclusions Perceptions of slipperiness and the subsequent rate of slipping were strongly associated. These findings suggest that safety professionals, risk managers and employers could use aggregated worker perceptions of slipperiness to identify slipping hazards and, potentially, to assess intervention effectiveness.

Same-level falls are one of the leading causes of injury in the workplace and in the general population. ${ }^{1}$ Consistent with earlier US Bureau of Labor Statistics projections, ${ }^{2}$ between 2004 and 2010 (the latest available data), the proportion of occupational fall injuries leading to days away from work has steadily increased. ${ }^{3}$ According to the 2011 Liberty Mutual Work Place Safety Index, between 1998 and 2009 , the direct cost of injuries from falls on the same level has also increased by $34.2 \% .{ }^{4}$ With an ageing worker population in most industrialised countries, the burden of occupational injuries due to falls may continue to rise in the future..$^{5-7}$

\section{What this paper adds}

- Same-level falls are a leading cause of work-related injury in developed countries, and slipping is the predominant cause of same-level falls.

- Prior research has shown modest correlations between objective measures (such as coefficient of friction) and subjective measures of slipperiness (such as worker perceptions). However, the degree of association between subjective measures and the actual risk of slipping in the workplace is heretofore unknown.

- If subjective measures and the risk of slipping at work were observed to have strong association, then subjective measures, which can be more practical to implement, could also be valuable in identifying and evaluating workplace slip and fall hazards.

- This is the first epidemiologic study to examine the association between worker perceptions of slipperiness and subsequent risk of slipping at work. We found that worker perceptions of slipperiness and the subsequent rate of slipping were strongly associated.

- Aggregated worker perceptions of slipperiness could provide a scalable approach to identifying slipping hazards and, potentially, assessing intervention effectiveness.

Slipping is a primary initiating event for samelevel falls and contributes to between $40 \%$ and $85 \%$ of fall-related occupational injuries. ${ }^{8-11}$ Grönqvist et al defined slipperiness as 'conditions underfoot which may interfere with human beings, causing a foot slide that may result in injury or harmful loading of body tissues due to a sudden release of energy'. ${ }^{12} 13$ They also stated that 'there is no unambiguous slipperiness measurement methodology'. One of the underlying reasons is the complex nature of human sensory motor interaction with the external environment. For the most part, researchers have generally used one of two approaches for the measurement of slipperiness: mechanical slip tests to measure coefficient of friction (COF) or human-centred subjective assessments. Subsequent interest has developed in comparing and contrasting the two approaches and studying their interaction. 
A comprehensive review of human-centred assessments is provided in Grönqvist et al. ${ }^{13}$

Several laboratory studies have examined the correlation between objective slipperiness measurement approaches (eg, COF using mechanical slip tests) and subjective measures (including having participants visually evaluate, walk on and/or work on the contrasted surfaces). These have reported positive correlations ranging from 0.75 to 0.99 between the two approaches. ${ }^{14-}$ ${ }^{16}$ However, these studies were conducted in laboratory settings with highly controlled and artificial conditions, generally involving a high contrast between conditions. Beyond the laboratory, Chang et al pioneered the study of the relationship between objective and subjective measures of slipperiness in active work environments. ${ }^{17}$ They investigated the relationship between measured friction levels and perception ratings of slipperiness in six major working areas of 10 fast-food restaurants in the USA, and observed a correlation coefficient of 0.34 , a more modest degree of association than those observed in the laboratory.

Recent studies have started to examine how objective measures are associated with the risk of slipping in active work environments. Courtney et al reported significantly reduced odds of slipping with increasing mean COF among limitedservice restaurant workers. ${ }^{18}$ Verma et al reported a prospective cohort study in which increasing mean COF was significantly associated with a reduced rate of slipping. ${ }^{19}$

However, few studies have examined how subjective approaches, such as worker ratings of slipperiness, are associated with the risk of slipping in active work environments. If subjective measures and the risk of slipping at work were observed to have strong association, then subjective measures (which can be more practical to implement) could also be valuable in identifying and evaluating workplace slip and fall hazards.

Slips and falls account for one of every three disabling injuries among US restaurant workers. ${ }^{20} 21$ Food service and drinking establishments are among the largest employers in the USA with about $7.5 \%$ of the total workforce. ${ }^{22}$ At this scale, restaurants contribute significantly to the overall occupational injury burden. ${ }^{3}$

As part of a large prospective cohort study of limited-service restaurant workers, ${ }^{19} 2324$ we examined the association between perception of slipperiness and risk of slipping. We hypothesised that the subsequent rate of slipping would be higher in restaurants with higher worker slipperiness ratings at baseline, and in areas within a restaurant with higher slipperiness ratings at baseline than other areas in the same restaurant.

\section{METHODS}

A prospective cohort study was conducted in 36 limited-service restaurants (establishments with North American Industry Classification System Code 72221) in the states of Connecticut, Massachusetts, New York, Pennsylvania, Tennessee and Wisconsin in the USA. Details of the overall study methods have been previously described and are therefore summarised here. ${ }^{19} 2324$ These restaurants belonged to three major chains and had similar main menu items. Several approaches were used to recruit the restaurants for the study. These included approaching chains, stores or franchisees that had previously been receptive to research studies by the investigative team members, approaching restaurant trade associations, direct solicitation of stores or franchisees, and outreach via the loss control department of a large worker's compensation insurance company.

A total of 475 workers were recruited from these restaurants in the years 2007 and 2008. Additional details of the study participants have been previously reported. ${ }^{19}$ The study was approved by the concerned institutional review boards on human experiments.

\section{Enrolment procedure}

Once permission to enrol a restaurant was received, members of the study team met onsite with the restaurant manager to explain the research study, administer a baseline manager survey, and set up an appointment to enrol and survey the restaurant's employees. Restaurant managers were given fliers advertising the study, with the date of the survey team's upcoming visit, which were posted in their employee break area. On the scheduled date, informed consents were obtained, participants were enrolled and surveys were conducted in the restaurant. Restaurant workers not working on the day of enrolment were encouraged to come to the restaurant sometime during that day, with their work shoes, if they were interested in participating in the study. The survey materials were made available in English, Spanish and Portuguese.

\section{Main exposure}

\section{Perception of slipperiness}

At baseline, participants were asked to rate floor slipperiness based on a typical workday in each restaurant kitchen in eight functional areas similar to those used by Chang et al ${ }^{17}{ }^{26}$ : front counter, drive-through, sandwich assembly, fryer, grill, sink, cooler/freezer and ice machine. A 4-point rating scale was used, where 1 was 'not slippery', 2 was 'a little slippery', 3 was 'more slippery', and 4 was 'very slippery'.

Slipperiness ratings (the ratings for each of the eight areas) were first averaged within each individual, and then individual overall ratings were averaged within each restaurant to calculate restaurant-level mean rating of perception of slipperiness (one measure for each restaurant). For area-level analysis, the slipperiness ratings from all participants for a given area were averaged within each restaurant to calculate mean area-level slipperiness ratings for each restaurant (eight values per restaurant).

\section{Outcome}

\section{Slipping}

A study team member carefully explained the definition of a slip to each study participant explaining that, 'A slip is simply a loss of traction of your foot-you can slip without falling'. After completing the baseline survey, participants were asked to report their slip experience every week for the following 12 weeks. Participants chose from one of three modalities for their weekly report: phone via an interactive voice response system, internet-based survey or completing and mailing paper survey forms.

Each subsequent week, participants reported the number of slips and the number of hours they worked during the previous week. Participants had to remember the incidents until the subsequent reporting day. The rate of slipping was the primary outcome of interest (total number of slips reported/total number of hours worked during follow-up). Participants also reported the functional area within the restaurant where they slipped.

\section{Covariates}

\section{Coefficient of friction}

COF was measured on three tiles in each of the eight areas in each restaurant using a Brungraber Mark II slip meter with Neolite padding. Details of the tile selection approach are discussed further by Verma. ${ }^{19}$ Two measurements were taken on 
each tile in the direction of traffic and parallel to the equipment. ${ }^{26}$ Floor COF was measured according to the F-1677-96 standard method published by the American Society for Testing and Materials ${ }^{27}$ along with protocol refinements recommended by Chang. ${ }^{28}$ Measurement results were averaged at the restaurant level to calculate each restaurant's mean COF.

\section{Slip-resistant shoes}

Participants were asked to remove their right shoe for direct observation and photograph. Since clear classification criteria for slip-resistant shoes could not be found in the literature, shoes were classified as slip-resistant if the manufacturer indicated them to be so by embossing or printing 'slip resistant' on the sole. Any participant who was not wearing the usual work shoes on the day of the survey was categorised as a non-slip-resistant shoe user $(n=20)$.

\section{Worker and job characteristics}

Demographic information about each participant was collected, including age, gender, education and primary language. Information about their weight and height was used to calculate body mass index (BMI). Participants also reported their job tenure at the restaurant.

\section{Data analysis}

In this study, two main associations were explored: first, the association between restaurant-level perception of slipperiness and the rate of slipping, and second, the association between area-level perception of slipperiness and the rate of slipping.

\section{Association between restaurant-level perception of slipperiness} and rate of slipping

Restaurants recruited in the study were clustered within chains, and workers were clustered within restaurants. To account for clustering of participants within restaurants, a negative binomial generalised estimating equation model with compound symmetry covariance structure 29 was used to assess the association between the rate of self-reported slipping and restaurant-level perception of slipperiness. Two dummy variables for chains were included in the regression model to account for clustering of restaurants within chains. All covariates were selected a priori and were included in the model. Rate ratios (RR) for the main effects and their $95 \%$ CI based on robust SE estimates are presented.

\section{Association between area-level perception of slipperiness and rate of slipping}

In this study, participants reported the areas of their slips. However, we only collected information on hours worked at the restaurant and did not collect information on the hours worked in each area. Therefore, for area-level analysis, we assumed that participants worked equal numbers of hours at each area. For example, if an employee worked a total of $216 \mathrm{~h}$ during follow-up, we assumed that this employee spent $27 \mathrm{~h}$ in each of the eight areas (216/8).

A sensitivity analysis was also performed based on primary areas of work. Participants reported their primary areas of work at baseline. If an area was not reported as a primary area of work, five percent of the total work time was allotted to that area, and the remaining work time was equally distributed among primary areas of work. For example, if a participant reported primarily working in five of the eight areas, the three areas that were not primary areas of work were allotted $15 \%$ of the total work time ( $5 \%$ each), and the remaining $85 \%$ of the work time was equally distributed among the five primary working areas (each primary area in this example was allotted $17 \%$ of the work time).

Slips were clustered within each individual, hence, the individual participant was identified as the cluster for the area-level analysis. To account for this clustering, a negative binomial generalised estimating equations model with compound symmetry covariance structure $^{29} 30$ was used to assess the association between the rate of self-reported slipping and within-restaurant area-level perception of slipperiness. Two dummy variables for chains were included in the regression model to account for clustering of restaurants within chains. All the main effects were selected a priori and were included in the model. RR for the main effects, and their 95\% CI based on robust SE estimates are presented. All statistical analyses were done using the SAS system V.9.2 (SAS Institute, Inc, Cary, North Carolina, USA).

\section{RESULTS}

Out of 475 participants, 422 reported at least 1 week of follow-up data. On average, 9.8 weeks of data were collected for each worker (median=11). table 1 presents the demographic information for participants who provided at least 1 week of follow-up data and those who did not. The mean age of participants who reported at least 1 week of follow-up data was 31.5 years (range $=15-78)$, and $22 \%$ were 19 years old or younger. More than two-thirds of the participants were women $(68 \%)$. The primary language of $89 \%$ of participants was English, 9\% was Spanish, and 2\% was Portuguese. Participants reported working an average of $34 \mathrm{~h}$ per week, and mean job tenure in their restaurant was 37 months (median=18). Participants with no follow-up data were younger, more likely to be men, less likely to be English speaking and less likely to have some college education than participants with follow-up data. The prevalence of slip-resistant shoe use and mean perception ratings were similar in those with no follow-up, and those with at least 1 week of follow-up data.

On a 4-point scale where 1 was 'not slippery' and 4 was 'very slippery', average restaurant-level perception of slipperiness was 1.9, ranging from 1.3 to 2.3. Average area-level perception of slipperiness was also 1.9; however, it ranged from 1.0 to 3.7. Area-level perception of slipperiness and objective COF were weakly correlated $(\mathrm{r}=-0.16$, $\mathrm{p}$ value $<0.01)$. The sink and fryer areas were rated most slippery with average slipperiness ratings of 2.4 each, and the front counter and drive-through areas were rated as least slippery with ratings of 1.3 and 1.4, respectively. The remaining average area values were rated as follows: grill, 2.1; ice machine, 1.9; cooler/freezer, 1.8 and sandwich assembly 1.7 . The front counter and drive-through were also the primary areas of work most frequently reported by participants $(70.9 \%$ and $70.1 \%$, respectively).

The total number of slips reported during the follow-up was 1168 , and the total number of hours worked was 105240 , resulting in an overall rate of slipping of 0.44 slips per 40 working hours. The mean of individual slipping rate was 0.69 slips per 40 working hours (median $=0.14$ ) or 34.5 slips per full-time employee per year. ${ }^{19}$

Restaurant-level mean perception of slipperiness was significantly associated with rate of slipping in the unadjusted regression model (table 2). In the multivariate model that adjusted for age, gender, BMI, education, primary language, mean COF, use of slip-resistant shoes and restaurant chain, a 1-point increase in the mean restaurant-level perception of slipperiness was associated with a 2.71 times increase in the rate of slipping (95\% CI 1.25 to 5.87) (table 2). Increases in mean COF and use of slip-resistant shoes were also associated with reduced rate of slipping (table 2). 
Table 1 Demographic characteristics of participants with no follow-up versus participants with at least 1 week of follow-up

\begin{tabular}{|c|c|c|c|}
\hline & $\begin{array}{l}\text { Participants with } \\
\text { no weekly survey } \\
(n=53)\end{array}$ & $\begin{array}{l}\text { Participants with at } \\
\text { least one weekly } \\
\text { survey }(n=422)\end{array}$ & p Value \\
\hline \multicolumn{4}{|l|}{ Age (years) } \\
\hline Mean (SD) & $25.5(10.6)$ & $31.5(13.4)$ & $<0.01$ \\
\hline Women (n, \%) & $26(49.1)$ & $288(68.3)$ & $<0.01$ \\
\hline \multicolumn{4}{|c|}{ Body mass index ${ }^{*}(n, \%)$} \\
\hline $\begin{array}{r}18.5 \text { or less } \\
\text { (underweight) }\end{array}$ & $1(1.9)$ & $13(3.1)$ & 0.30 \\
\hline $\begin{array}{l}18.5-24.9 \\
\text { (normal) }\end{array}$ & $24(45.3)$ & $157(37.2)$ & \\
\hline $\begin{array}{r}25.0-34.9 \\
\text { (overweight) }\end{array}$ & $22(41.5)$ & $185(43.8)$ & \\
\hline $\begin{array}{l}35.0-39.9 \\
\text { (obese) }\end{array}$ & $1(1.9)$ & $40(9.5)$ & \\
\hline $\begin{array}{l}40+ \\
\text { (extremely obese) }\end{array}$ & $5(9.4)$ & $27(6.4)$ & \\
\hline \multicolumn{4}{|c|}{ Primary language $(n, \%)$} \\
\hline English & $43(81.1)$ & 377 (89.3) & 0.01 \\
\hline Spanish & $5(9.4)$ & $36(8.5)$ & \\
\hline Portuguese & $5(9.4)$ & $9(2.1)$ & \\
\hline \multicolumn{4}{|l|}{ Education (n, \%) } \\
\hline $\begin{array}{l}\text { Never } \\
\text { attended school }\end{array}$ & $0(0.0)$ & $6(1.42)$ & $<0.01$ \\
\hline Grades 1-11 & $29(54.7)$ & $126(29.9)$ & \\
\hline $\begin{array}{l}\text { High school } \\
\text { grad/GED }\end{array}$ & $19(35.9)$ & 167 (39.6) & \\
\hline $\begin{array}{l}\text { Some college or } \\
\text { above }\end{array}$ & $5(9.4)$ & $123(29.2)$ & \\
\hline \multicolumn{4}{|c|}{ Job tenure (months) } \\
\hline Mean (SD) & $24.7(41.5)$ & $36.8(48.7)$ & 0.08 \\
\hline \multicolumn{4}{|l|}{ Weekly work hours } \\
\hline Mean (SD) & $31.8(10.2)$ & $34.4(11.2)$ & 0.10 \\
\hline \multicolumn{4}{|c|}{ Slip-resistant shoes (n, \%) } \\
\hline Yes & $34(64.2)$ & $286(67.8)$ & 0.60 \\
\hline No & $19(35.8)$ & $136(32.2)$ & \\
\hline \multicolumn{4}{|c|}{ Average perception of slipperiness } \\
\hline Mean (SD) & $1.88(0.55)$ & $1.90(0.54)$ & 0.80 \\
\hline
\end{tabular}

Increased within-restaurant area-level mean perception of slipperiness ratings were significantly associated with an increased rate of slipping in both the unadjusted and the adjusted models (table 3). In the multivariate model which adjusted for covariates, a 1-point increase in the mean area-level perception was associated with a 2.92 times increase in the rate of slipping $(95 \% \mathrm{CI}$ 2.41 to 3.54$)$. In the sensitivity analysis, which took into account primary areas of work and allocated time worked in each area, accordingly, the association between area-level perception of slipperiness and the rate of slipping remained significant but was somewhat stronger (rate ratio $3.88,95 \%$ CI 3.21 to 4.69 ).

\section{DISCUSSION}

This study provides the first evidence that aggregate perception of slipperiness measured at baseline is associated with the subsequent risk of self-reported slipping (over a 12 -week period). We also found that work areas that were rated more slippery compared with other areas in the same restaurants at baseline had a higher incidence of prospectively reported slipping.
Table 2 Rate ratios (RR) and their 95\% Cl from univariate and multivariate regression models modelling the rate of slipping with restaurant-level perception of slipperiness

\begin{tabular}{|c|c|c|c|c|}
\hline & \multicolumn{2}{|c|}{ Univariate } & \multicolumn{2}{|c|}{ Multivariate } \\
\hline & $\mathbf{R R}$ & $95 \% \mathrm{Cl}$ & $\mathbf{R R}$ & $95 \% \mathrm{Cl}$ \\
\hline $\begin{array}{l}\text { Mean restaurant-level perception } \\
\text { of slipperiness ( } 1 \text { point)* }\end{array}$ & 4.78 & $\begin{array}{l}1.36 \text { to } \\
16.81\end{array}$ & 2.71 & 1.25 to 5.87 \\
\hline $\begin{array}{l}\text { Mean coefficient of friction } \\
(0.1)^{*}\end{array}$ & & & 0.77 & 0.65 to 0.92 \\
\hline \multicolumn{5}{|l|}{ Slip-resistant shoes* } \\
\hline Yes & & & 0.46 & 0.34 to 0.62 \\
\hline No & & & 1 & - \\
\hline Age (10 years) ${ }^{*}$ & & & 0.70 & 0.58 to 0.85 \\
\hline Body mass index (5 units) & & & 1.00 & 0.90 to 1.11 \\
\hline \multicolumn{5}{|l|}{ Gender } \\
\hline Men & & & 0.93 & 0.67 to 1.28 \\
\hline Women & & & 1 & - \\
\hline Job tenure (12 months) & & & 0.99 & 0.94 to 1.05 \\
\hline \multicolumn{5}{|l|}{ Education } \\
\hline Never attended ${ }^{*}$ & & & 4.15 & $\begin{array}{l}1.17 \text { to } \\
14.75\end{array}$ \\
\hline Grades 1-11 & & & 1.20 & 0.83 to 1.72 \\
\hline High school grad/GED & & & 0.98 & 0.65 to 1.48 \\
\hline Some college and above & & & 1 & - \\
\hline \multicolumn{5}{|l|}{ Language } \\
\hline Portuguese & & & 0.31 & 0.04 to 2.55 \\
\hline Spanish* & & & 0.45 & 0.29 to 0.70 \\
\hline English & & & 1 & - \\
\hline \multicolumn{5}{|l|}{ Chain } \\
\hline Chain $1^{*}$ & & & 0.66 & 0.47 to 0.91 \\
\hline Chain 2 & & & 0.81 & 0.62 to 1.06 \\
\hline Chain 3 & & & 1 & - \\
\hline
\end{tabular}

Humans perceive floor slipperiness via many different mechanisms which can include sensory (eg, visual perception, proprioception, tactile feedback, etc), experiential (eg, prior history of slipping or falling by the respondent or observation of a coworker, a near miss, reports of slippery conditions by others, etc), and other factors. A few studies have shown that people adjust their gait when walking on slippery surfaces. ${ }^{31} 32$ Others have found humans to be relatively capable discriminators of floor friction when presented with classic psychophysical test paradigms, such as paired comparison scenarios under controlled, high contrast conditions such as dry, wet and contaminated. $^{12} \quad 13$ 33-36 However, since these studies have been conducted in highly controlled laboratory environments, their generalisability to actual work settings has been limited. The current study provides evidence from actual work environments on the association between workers' subjective perception of slipperiness and subsequent risk of slipping.

Both the mechanical slip-test approach which measures COF and human-centred subjective assessment approach have their strengths and limitations. Although susceptible to devicedependent measurement error and interoperator variability, mechanical COF measurement approaches are generally more precise and less susceptible to systematic individual biases. However, there are human aspects to slipping and fallingincluding visual cues, proprioception, gait adaptation, motor control, adaptive balance, memory, etc-that cannot be accounted for by COF alone. In addition, transient floor 
Table 3 Rate ratios (RR) and their $95 \% \mathrm{Cl}$ from univariate and multivariate regression models modelling the rate of slipping with within-restaurant area-level perception of slipperiness

\begin{tabular}{|c|c|c|c|c|c|c|}
\hline & \multicolumn{2}{|c|}{ Univariate } & \multicolumn{2}{|c|}{ Multivariate } & \multicolumn{2}{|c|}{ Sensitivity analysis } \\
\hline & $\mathbf{R R}$ & $95 \% \mathrm{Cl}$ & RR & $95 \% \mathrm{Cl}$ & $\mathbf{R R}$ & $95 \% \mathrm{Cl}$ \\
\hline Mean area-level perception of slipperiness (1 point) ${ }^{*}$ & 3.13 & 2.54 to 3.86 & 2.92 & 2.41 to 3.54 & 3.88 & 3.21 to 4.69 \\
\hline Mean coefficient of friction $(0.1)^{*}$ & & & 0.75 & 0.60 to 0.94 & 0.75 & 0.61 to 0.92 \\
\hline \multicolumn{7}{|l|}{ Slip-resistant shoes } \\
\hline Yes* & & & 0.51 & 0.35 to 0.75 & 0.49 & 0.34 to 0.72 \\
\hline No & & & 1 & - & 1 & - \\
\hline Age $(10 \text { years })^{*}$ & & & 0.71 & 0.59 to 0.85 & 0.70 & 0.58 to 0.84 \\
\hline Body mass index (5 units) & & & 0.99 & 0.86 to 1.14 & 0.95 & 0.82 to 1.10 \\
\hline \multicolumn{7}{|l|}{ Gender } \\
\hline Men & & & 1.06 & 0.74 to 1.52 & 1.15 & 0.80 to 1.64 \\
\hline Women & & & 1 & - & 1 & \\
\hline Job tenure (12 months) & & & 0.96 & 0.91 to 1.02 & 0.96 & 0.91 to 1.02 \\
\hline \multicolumn{7}{|l|}{ Education } \\
\hline Never attended & & & 0.18 & 0.02 to 1.52 & 0.20 & 0.03 to 1.54 \\
\hline Grades 1-11 & & & 1.00 & 0.67 to 1.50 & 1.01 & 0.67 to 1.53 \\
\hline High school grad/GED & & & 0.92 & 0.61 to 1.39 & 0.85 & 0.56 to 1.29 \\
\hline Some college and above & & & 1 & - & 1 & \\
\hline \multicolumn{7}{|l|}{ Language } \\
\hline Portuguese & & & 0.40 & 0.07 to 2.42 & 0.46 & 0.07 to 3.09 \\
\hline Spanish* & & & 0.27 & 0.10 to 0.72 & 0.25 & 0.09 to 0.68 \\
\hline English & & & 1 & - & 1 & - \\
\hline \multicolumn{7}{|l|}{ Chain } \\
\hline Chain 1 & & & 0.73 & 0.42 to 1.27 & 0.78 & 0.44 to 1.36 \\
\hline Chain $2^{*}$ & & & 0.67 & 0.45 to 0.98 & 0.67 & 0.46 to 1.00 \\
\hline Chain 3 & & & 1 & - & 1 & - \\
\hline
\end{tabular}

Note: Limited-service restaurant workers, 2007-2008.

* Significant at $\alpha$ level of 0.05 .

contamination plays an important role in determining slipperiness of an area. Point-in-time COF measurement may depend on floor conditions at the time of measurement and may not take into account the frequency and variability of contamination. Individual's perceptions of slipperiness, on the other hand, are shaped by experiences over time, and may be particularly valuable in occupational settings where workers have a comparatively long and recurring experience of working and walking in an area. Comparatively speaking, COF measurements require specialised expertise and equipment, while perception scales, properly constructed, are potentially less resource intensive and more scalable/accessible. Perception of slipperiness scales could, potentially, be used by slip and fall researchers, safety practitioners and employers to readily identify areas with high slipping hazards without waiting for an actual slip and/or fall injury to occur. Such scales could also potentially be applied to the evaluation of slip and fall intervention effectiveness (given appropriate control for bias).

We also observed that perception of slipperiness and mean COF were independently associated with the rate of slipping. Thus, it can also be argued that these measures are complimentary to each other, and, where both can be made available, provide more comprehensive slip risk assessment than either one alone.

\section{Limitations and strengths}

The study was conducted in limited-service restaurants, which have a relatively high rate of slips and falls. It is unclear to what extent the study results are generalisable to other work environments, particularly those with a low slip and fall frequency.
Another limitation of the study is that we assumed equal time spent at each work area. If workers spent more time in slippery areas, the association between area-level perception of slipperiness and rate of slipping could have been biased. However, in the sensitivity analysis that took into account primary areas of work, the rate ratio was even higher. Secondly, front counter and drive-through were reported by the highest number of workers as their primary areas of work, and these were rated the least slippery. Therefore, it is unlikely that the association between area-level perception of slipperiness and rate of slipping can be fully explained by time spent in slippery areas.

Additionally, we measured perception as a 'black box' variable herein. We expected perception to integrate/include all the experiences and sensations that were part of a worker's exposure at an individual level. However, our study was not designed to assess which particular experiences or sensations influenced individual-level perception. These factors and their influence on perception are a potential subject for future research in this area.

This study had several strengths, chief of which was its prospective design with participant reporting of slipping over a 12-week period. Participants were asked to rate slipperiness at the beginning of the baseline questionnaire. It is unlikely that participants were then able to recall their baseline perception ratings during the subsequent prospective study period, and that such recall affected their reporting of slips. Additionally, restaurants belonging to three major chains, and across six different US states participated in the study. The survey materials were made available in three different languages, thus increasing the generalisability of the study findings. 


\section{CONCLUSION}

This is the first prospective cohort study to examine the association between subjective perception of slipperiness and the risk of slipping in active work environments. Our results indicate a strong, positive association between average restaurant-level and area-level perception of slipperiness, and subsequent rates of slipping. The findings suggest that safety professionals, risk managers and employers could potentially use aggregated worker perceptions of slipperiness as a scalable approach to identifying areas with high slipping hazards and, potentially, to assessing intervention effectiveness. While further research is needed to confirm our findings, such a scalable, efficient approach to risk assessment could substantially impact same-level falls in the global workplace.

Acknowledgements The authors are indebted to Marvin Dainoff and Raymond McGorry for their constructive criticisms of earlier drafts of the manuscript. The authors would like to thank Jacob Banks, Christopher Brunette, Albert Chang, Helen Corns, Niall O'Brien, Greg Schultz, Joanna Willetts, Joe Ferreira, Sandra Goncalves, Gabriela Herscovici, Patricia Boelsen and Monica Colon who contributed to the collection of data or study administration. The authors would also like to thank Margaret Rothwell for editorial support and proofreading of the manuscript.

Contributors TKC contributed to conception and design of the study, data analysis and interpretation, and writing of the manuscript. SKV contributed to conception and design of the study, data acquisition, data analysis and interpretation, and drafting of the manuscript. W-RC contributed to conception and design of the study and revising of the manuscript. Y-HH contributed to conception and design of the study and revising of the manuscript. DAL contributed conception and design of the study and revising of the manuscript. MJB contributed to the study design, data acquisition and revising of the manuscript. MJP contributed to conception and design of the study and revising of the manuscript.

Competing interests None.

Ethics approval The study was approved by the Institutional Review Board of Liberty Mutual Research Institute for Safety and the Office of Human Research Administration at the Harvard School of Public Health.

Provenance and peer review Not commissioned; externally peer reviewed.

Open Access This is an Open Access article distributed in accordance with the Creative Commons Attribution Non Commercial (CC BY-NC 3.0) license, which permits others to distribute, remix, adapt, build upon this work non-commercially, and license their derivative works on different terms, provided the original work is properly cited and the use is non-commercial. See: http://creativecommons.org/ licenses/by-nc/3.0/

\section{REFERENCES}

1 Finkelstein EA, Phaedra CS, Miller TR. The incidence and economic burden of injuries in the United States. New York, NY: Oxford University Press, 2006.

2 Nestoriak N, Ruser J. Emerging labor market trends and workplace safety and health. CRIW Conference on Labor in the New Economy, 2007.

3 Bureau of Labor Statistics-United States Department of Labor, Case and Demographic Characteristics for Work-related Injuries and IIInesses Involving Days Away From Work. http://www.bls.gov/iif/oshcdnew.htm\#00f (accessed 2012).

4 Liberty Mutual Research Institute for Safety, 2011 Workplace Safety Index. http:// www.libertymutualgroup.com/omapps/ContentServer? $c=$ cms_document\&pagename=LMGResearchlnstitute/cms_document/ ShowDoc\&cid=1138365240689 (accessed 2 Jan 2012).

5 U.S. Department of Labor, U.S. Bureau of Labor Statistics 2009, Monthly Labor Review.http://www.bls.gov/opub/mlr/2009/11/mlr200911.pdf (accessed 2012).

6 McNamee R, Kemmlert K, Lundholm L, et al. Injuries after falls at work in the United Kingdom and Sweden with special reference to fractures in women over 45. Occup Environ Med 1997;54:785-92.

7 Davies JC, Manning DP, Kemp GJ, et al. The rising number of underfoot accidents after the menopause causes both fractures and non-fracture injuries. QJM 2001;94:699-707.
8 Courtney TK, Sorock GS, Manning DP, et al. Occupational slip, trip, and fall-related injuries-can the contribution of slipperiness be isolated? Ergonomics 2001:44:1118-37.

9 Verma SK, Lombardi DA, Chang WR, et al. A matched case-control study of circumstances of occupational same-level falls and risk of wrist, ankle and hip fracture in women over 45 years of age. Ergonomics 2008;51:1960-72.

10 Manning DP, Ayers I, Jones $C$, et al. The incidence of underfoot accidents during 1985 in a working population of 10,000 Merseyside people. J Occup Accid 1988; 10:121-30.

11 Kemmlert K, Lundholm L. Slips, trips and falls in different work groups with reference to age. Saf Sci 1998;28:59-75

12 Grönqvist R, Chang WR, Courtney TK, et al. Measurement of slipperiness: fundamental concepts and definitions. Ergonomics 2001;44:1102-17.

13 Grönqvist R, Abeysekera J, Gard G, et al. Human-centred approaches in slipperiness measurement. Ergonomics 2001;44:1167-99.

14 Swensen EE, Purswell JL, Schlegel RE, et al. Coefficient of friction and subjective assessment of slippery work surfaces. Hum Factors 1992;34:67-77.

15 Grönqvist R, Hirvonen M, Tuusa A. Slipperiness of the shoe-floor interface: comparison of objective and subjective assessments. App/ Ergon 1993;24:258-62.

16 Li KW, Chang WR, Leamon TB, et al. Floor slipperiness measurement: friction coefficient, roughness of floors, and subjective perception under spillage conditions. Saf Sci 2004;42:547-65.

17 Chang WR, Huang YH, Li KW, et al. Assessing slipperiness in fast-food restaurants in the USA using friction variation, friction level and perception rating. App/ Ergon 2008:39:359-67.

18 Courtney TK, Verma SK, Huang YH, et al. Factors associated with worker slipping in limited service restaurants. Inj Prev 2010;16:36-41.

19 Verma SK, Chang WR, Courtney TK, et al. A prospective study of floor surface, shoes, floor cleaning and slipping in U.S. limited-service restaurant workers. Occup Environ Med 2011;68:279-85.

20 Leamon TB, Murphy PL. Occupational slips and falls: more than a trivial problem. Ergonomics 1995:38:487-98.

21 Filiaggi AJ, Courtney TK. Restaurant hazards - practice-based approaches to disabling occupational injuries. Prof Safety 2003;48:18-23.

22 Bureau of Labor Statistics 2010, Workplace Injury and IIIness Summary (USDL-11-1502) -Table 4. Number of cases and incidence rate of nonfatal occupational injuries and illnesses for industries with 100,000 or more cases. 2010. http://www.bls.gov/news.release/osh.t04.htm (accessed 2011).

23 Verma SK, Lombardi DA, Chang WR, et al. Rushing, distraction, walking on contaminated floors and risk of slipping in limited-service restaurants: a casecrossover study. Occup Environ Med 2011;68:575-81.

24 Verma SK, Chang WR, Courtney TK, et al. Workers' experience of slipping in U.S. limited-service restaurants. J Occup Environ Hyg 2010;7:491-500.

25 Courtney TK, Huang YH, Verma SK, et al. Factors influencing restaurant worker perception of floor slipperiness. J Occup Environ Hyg 2006;3:593-9.

26 Chang WR, Li KW, Filiaggi A, et al. Friction variation in common working areas of fast-food restaurants in the USA. Ergonomics 2008;51:1998-2012.

27 American Society for Testing and Materials. F1677-05 standard test method for using a Portable Inclineable Articulated Strut Slip Tester (PIAST). In: Annual Book of ASTM Standards. West Conshohochen, PA: American Society for Testing and Materials, 2005

28 Chang WR. The effects of slip criterion and time on friction measurements. Saf Sci 2002;40:593-611.

29 Liang KY, Zeger SL. Longitudinal data analysis using generalized linear models. Biometrika 1986;73:13-22

30 Zeger SL, Liang KY. Longitudinal data analysis for discrete and continuous outcomes. Biometrics 1986;42:121-30.

31 Cham R, Redfern MS. Changes in gait when anticipating slippery floors. Gait Posture 2002;15:159-71

32 Fong DTP, Hong Y, Li J-X. Human walks carefully when the ground dynamic coefficient of friction drops below 0.41. Saf Sci 2009;47:1429-33.

33 Myung R, Smith JL, Leamon TB. Subjective assessment of floor slipperiness. Int J Ind Ergon 1993;11:313-19.

34 Chiou Sy, Bhattacharya A, Succop PA. Effect of workers' shoe wear on objective and subjective assessment of slipperiness. Am Ind Hyg Assoc J 1996;57:825-31.

35 Tisserand M. Progress in the prevention of falls caused by slipping. Ergonomics 1985:28:1027-42.

36 Cohen HH, Cohen DM. Psychophysical assessment of the perceived slipperiness of floor tile surfaces in a laboratory setting. J Saf Res 1994;25:19-26. 